\title{
ESBOÇO DE UMA FENOMENOLOGIA DA VIOLÊNCIA
} SEGUNDO HEIDEGGER

\author{
Felipe Ramos Gall \\ Mestrando em Filosofia pela PUC-Rio \\ Bolsista do CNPq
}

\begin{abstract}
Resumo: Intenta-se aqui uma abordagem do tema da violência em seu sentido fenomenológico, e, portanto, ontológico, segundo a compreensão de Martin Heidegger. Ver-se-á que a violência, mais do que um problema social ou político, é, originariamente, um elemento estrutural do ser do homem.
\end{abstract}

O tema da violência é pensado, de modo geral, no âmbito da filosofia política e das ciências sociais. Nesse sentido, o questionamento direciona-se para as manifestações da violência na sociedade, na história, ou até mesmo pensa-se a violência como uma categoria política ou um aparelho estatal. Tais não serão o caso aqui. O que aqui se pretende é trazer à tona a essência da violência em seu sentido ontológico e, portanto, fenomenológico. 
ANALÓGOS, Rio de Janeiro, Edição Especial, 2017

Como o título já aponta, deve-se ter em mente que tal exercício fenomenológico será aqui meramente esboçado, e que, por conseguinte, de modo algum intenta-se aqui esgotar o fenômeno da violência. Esboço, no entanto, não no sentido de um improviso, de algo temporário feito apressada ou toscamente, mas sim no sentido etimológico da palavra grega skhédios (daí os termos sketch, no inglês, e Skizze, no alemão), que significa: aproximar-se, chegar perto de, quase alcançar.

Estabelecido isso, questionar-se-á, por conseguinte, a essência da violência. De modo geral, a pergunta pela essência de algo diz respeito a o quê a coisa é, sua quididade, ou, dito de outro modo, sua natureza. Não será esse o sentido de essência a ser considerado aqui. Não obstante, ainda esse sentido tradicional resguarda em si algo de originário. Pois, em que sentido pode a palavra natureza designar o que alguma coisa é? Certamente não no sentido habitual de natureza como meio ambiente ou como objeto cujas leis são estudadas pela física moderna. Natureza, natura, foi o modo como os latinos traduziram a palavra grega phýsis, termo utilizado pelos pensadores gregos para designar o ente em sua totalidade, e, por conta disso, recebeu a conotação de essência, pois diz o que algo é. Tal tradução, no entender de Heidegger, não é suficiente para expressar o conteúdo daquilo que os gregos pensavam com essa palavra. Qual seria, então, essa força designativa que se perde na tradução de phýsis por natura? De acordo com Heidegger, lexicalmente, phýsis, que vem de phýo, pode mesmo significar, tal como natura, nascer, gerar, crescer. No entanto, crescer aqui não tem nenhum sentido quantitativo, de se tornar mais ou maior. 
O que diz então a palavra phýsis? Diz: o desabrochar, o emergir de dentro de si mesmo, (...) aquilo que ao abrir-se se desdobra, que se manifesta em tal desdobramento, nele se mantendo e permanecendo, em síntese: o vigorar que emergindo permanece (das aufgehend-verweilende Walten). (...) No entanto, a phýsis, o que emergindo vigora (aufgehende Walten) (...) não deverá ser entendida como um processo qualquer entre outros que observamos no ente. A phýsis é o próprio Ser, em virtude do qual o ente se torna observável e permanece'.

O tornar-se observável do ente, manifestar-se, é dito em grego pháinesthai, de onde deriva o termo phainómenon, fenômeno. Pháinesthai, por sua vez, é a forma média/passiva de pháino, que significa "trazer para a luz do dia, pôr no claro. Pháino pertence à raiz pha- como, por exemplo, phôs, a luz, a claridade, isto é, o elemento, o meio, em que alguma coisa pode vir a se revelar e a se tornar visível em si mesma"2. Fenômeno, portanto, é o mostrar-se como do ente, sua manifestação. Embora o conceito de fenômeno (e de manifestação) em Heidegger seja mais complexo que isso, esse sentido supramencionado bastará para o que aqui se intenta.

Ora, propõe-se aqui aproximar-se de uma fenomenologia da violência. Isso significa elucidar o modo de ser da violência, descrever sua essência, mas não, como dito, no sentido de um quid. "[A fenomenologia] não caracteriza a quididade real dos objetos da investigação filosófica mas o

\footnotetext{
${ }^{1}$ HEIDEGGER, M. Introdução à Metafísica, pp. 22-23.

${ }^{2}$ HEIDEGGER. M. Ser e Tempo, p. 58.
} 
ANALÓGOS, Rio de Janeiro, Edição Especial, 2017

seu modo, como eles o são"3. Tal questionar exige um certo percurso, um caminho que, como caminho, não existe previamente, pois só passa a existir enquanto e quando é caminhado. Assim, a questão da violência mesma surgirá apenas quando for encontrada neste trilhar. Retomando-o, tem-se, assim, que a pergunta pela essência levou à ideia de fenômeno. Fenômeno diz respeito ao modo como o ente, tò ón, vem à luz. Desse modo, alude ele tanto ao termo fenomenologia quanto ontologia, que, no fundo, querem dizer o mesmo: "Em seu conteúdo, a fenomenologia é a ciência do ser dos entes - é ontologia"4. Em ambos os casos, a relação com o lógos é evidente. Que significa lógos, portanto?

O primeiro sentido que vem à mente é aquele legado pela tradição, a saber: lógos significa palavra, verbo, discurso. Daí deriva a interpretação de lógos como "lógica", o pensar propriamente dito, possibilitando, desse modo, a tradução de lógos por razão, pensamento.

No entanto - diz Heidegger - lógos originariamente não significa discurso, nem dizer. Esta palavra não tem no seu significado qualquer referência imediata à linguagem. Lego, legein, legere em latim é a mesma palavra que a alemã "lesen"; "Ähren lesen" (colher espigas), "Holz lesen" (juntar ou apanhar lenha), "die Weinlese" (a vindima), "die Auslese" (a seleção); "ein Buch lesen" (ler um livro) é apenas um derivado de "lesen" no seu sentido original. "Lesen" significa: pôr uma coisa ao lado de outra, juntá-las num conjunto, sem síntese: coligir,

\footnotetext{
${ }^{3}$ Idem, ibidem, p. 57.

${ }^{4}$ Idem, ibidem, p. 68.
} 
ANALÓGOS, Rio de Janeiro, Edição Especial, 2017 compilar, colecionar (sammeln); ao fazê-lo, vai-se, ao mesmo tempo, distinguindo uma coisa da outra5.

Por conseguinte, Heidegger concluirá que lógos significa, originariamente, "(re)união (re)unificante, i.é, o que estando (re)unido (re)une, o (re)unificante originário. Lógos não significa aqui nem sentido nem palavra, (...) significa: a (re)união originariamente (re)unificante que vigora constantemente em si mesma" 6 . Em uma palavra: harmonia. Harmonia, na mitologia grega, era a filha de Ares, deus da guerra em seu sentido violento e brutal, com Afrodite, deusa do amor e da beleza. Há, intrínsecamente, algo de violento e belo na harmonia, de acordo com os gregos. A concórdia por ela gerada é fruto de um conflito, uma luta ou guerra. Assim é o lógos: uma "união [que] nunca é um simples ajuntamento e amontoamento. Ela mantém o que tende a dissociar-se e contrapor-se retido numa co-pertença. Não o deixa desagregar-se em mera dispersão"7. Por não ser um reles ajuntamento, é belo; por manter retido aquilo que se contrapõe, é violento. Com efeito, Heidegger assevera:

Enquanto retenção, o lógos tem o caráter do que vigora de modo penetrante (Durchwalten), da phýsis. A (re)união não dissolve o que é dominado pelo vigor penetrante (Durchwaltete) num vazio de in-contrastividade (Gegensatzlosigkeit), retendo-o antes, a partir da união do que tende a opor-se, na máxima agudeza da sua tensão8.

\footnotetext{
${ }^{5}$ HEIDEGGER, M. Introdução à Metafísica, p. 137.

${ }^{6}$ Idem, ibidem, p. 141.

${ }^{7}$ HEIDEGGER, M. Introdução à Metafísica, p. 148.

${ }^{8}$ Idem, ibidem.
} 
ANALÓGOS, Rio de Janeiro, Edição Especial, 2017

Ora, o que Heidegger está afirmando, na verdade, é que, enquanto unidade retentora em si mesma, o lógos é o próprio Ser. Daí ele afirmar que lógos possui o caráter da phýsis, onde phýsis também já havia sido compreendida como o Ser. Por conseguinte, phýsis e lógos são o mesmo. Todavia, o que entende Heidegger por "mesmo"? Será no sentido ordinário de igualdade? Certamente não. "Mesmo", para Heidegger, significa: fazer parte da mesma experiência originária, o pertencimento comum que forma uma unidade entre eles. Dito de outro modo: phýsis e lógos são diferentes entre si, mas são o mesmo em relação a uma unidade originária, onde phýsis só é phýsis quando em comum pertencimento ao lógos e vice versa.

Ora, mas a harmonia reunida do ser que vigora não é justamente o ente que se mostra, ou seja, o fenômeno? Ademais, dado que "o conceito oposto de fenômeno é o conceito de encobrimento" 9 e, dado que Heidegger entende a verdade, ontologicamente, como alétheia, des-encobrimento (Unverborgenheit), pode-se concluir, de modo talvez apressado mas não arbitrariamente, que phýsis, lógos, pháinesthai e alétheia são o mesmo.

A verdade (alétheia), no entanto, nunca é, para Heidegger, um estado de fato. O que está aí de fato, presente, já está desde sempre na verdade. A verdade mesma é o vir à luz, o manifestar-se do ser, o perene vir à presença dos entes. Nesse sentido, a verdade não só não é um estado de fato, mas, antes, o fundamento de todo e qualquer estado de fato. O irromper do ser é um acontecimento reservado a um ente privilegiado, a um ente que, ôntico, é ontológico, isto é, sendo, é também ser. Heidegger chama esse ente de

\footnotetext{
${ }^{9}$ HEIDEGGER. M. Ser e Tempo, p.66.
} 
ANALÓGOS, Rio de Janeiro, Edição Especial, 2017 Dasein, "presença" ou "ser-aí", que é o ente que nós mesmos já sempre somos originariamente. O Dasein é o ente capaz de compreender o ente enquanto ente, e esse enquanto é aí decisivo: enquanto significa ligação, abertura. O acesso ao ente enquanto tal diz, portanto, que o Dasein é ligado e aberto ao ser. Abertura é outro modo para se dizer verdade. Abertura, pois, é interesse, em duplo sentido: é interesse porque as coisas já sempre importam, há já sempre uma compreensão de ser e uma lida com as coisas, e é inter-esse, o entre-ser no qual já se está sempre dentro. No entanto, esse sentido originário do homem, enquanto tal ente dotado de Dasein, perde-se ao defini-lo, tal como o faz a tradição, como dzôon lógon ékhon, isto é, animal rationale, animal racional. Heidegger assevera que

Nesta definição do homem consta o lógos, embora de uma forma absolutamente irreconhecível e num contexto muito estranho. (...) [Tal definição] é, no fundo, zoológica. (...) todavia, no âmbito dessa definição edificou-se a doutrina ocidental do homem, toda a psicologia, ética, gnoseologia e antropologia. (...) Mas sendo uma definição toda portadora (alles tragende) do homem já uma decadência, para nem sequer se falar da sua posterior interpretação, é por isso mesmo que, enquanto pensarmos e interrogarmos dentro da órbita de visão por ela pré-traçada (...) [não teremos] acesso ao espaço em que acontece o aparecimento inicial e a consolidação da essência do homem ${ }^{10}$.

Com efeito, buscando uma aproximação mais originária do Ser do homem, Heidegger recorrerá não ao pensamento filosófico, mas sim a uma

\footnotetext{
${ }^{10}$ HEIDEGGER, M. Introdução à Metafísica, pp. 156-157.
} 
ANALÓGOS, Rio de Janeiro, Edição Especial, 2017 experiência grega fundamental poético-pensante (dichterisch-denkend), qual seja: a tragédia Antígona, de Sófocles. O primeiro coro (vv. 332-375) começa assim: "Múltiplo é o estranho, nada, porém,/para além do homem, de mais estranho há"11. O termo ali traduzido por "estranho" é, na tradução alemã feita por Heidegger, Unheimlich. "Estranho", entretanto, é apenas um dos sentidos que esse termo possui em alemão. Das Unheimliche pode significar, além de estranho e incrível, também inquietante, sinistro, lúgubre, medonho. Contudo, qualquer que seja o termo escolhido para a tradução do termo, o homem seria o superlativo disso.

O homem é, numa palavra apenas: tò deinótaton, o que de mais estranho há. Este dizer concebe o homem pelos extremos limites e mais profundos abismos do seu Ser. (...) Somente a um idear poético-pensante se revela um tal Ser. (...) A palavra grega deinón e a nossa tradução necessitam aqui de uma explicação prévia. (...) Uma vez, deinón significa o terrível, mas não os pequenos terrores e, muito menos, tem aquele significado decadente, parvo e inútil com que hoje se usa entre nós a palavra, quando se diz 'terrivelmente engraçado' (furchtbar niedlich). Deinón é o terrível no sentido do vigorar imperar modo imponente (-s überwältigende Walten), o que provoca, de modo igual, o medo pânico (panischer Schrecken), o verdadeiro pavor (Angst), como o temor (Scheu) discreto, concentrado e vibrando em si mesmo. A imponência $(-s$ Gewaltige), o vigorar de modo imponente ( $-s$ Überwältigende) é o caráter essencial do próprio vigorar ( $-s$ Walten). Onde este irrompe, pode manter em si o seu poder imperioso. Todavia, não se torna por isso mais inofensivo, tornando-se antes ainda mais terrível e distante ${ }^{12}$.

\footnotetext{
${ }^{11}$ Idem, ibidem, p. 161.
}

${ }^{12}$ Idem, ibidem, p. 165. 
Deve-se aqui atentar para o fato de Heidegger enfatizar os termos Walten (vigorar, regra, norma, prevalecer), Gewaltige (imponente, tremendo) e Überwältigende (esmagador, opressivo, colossal). Todos esses termos estão relacionados a Gewalt (violência, poder).

Outra vez, porém, deinón significa a imponência no sentido daquilo que necessita e usa o poder da força e violência (Gewalt), que não só dispõe do poder da violência como também o aplica, agindo com violência (gewalt-tätig) sendo violento, na medida em que o uso da violência não só é feição fundamental do seu agir como também da sua existência ${ }^{3}$.

Por conseguinte, a phýsis, o ente no seu todo no sentido daquilo que vigora, é a imponência, o deinón no primeiro sentido. O homem, por sua vez, também é deinón na medida em que permanece exposto a esta imponência, já que pertence essencialmente ao Ser. No entanto, por outro lado, o homem também é deinón em outro sentido e ao mesmo tempo, porque ele é, tal como supracitado, aquele que age com violência. Ele, estando em consonância com o lógos (homologia), reune o que vigora e permite que este se abra, entrando na evidencialidade. O homem é aquele que age com violência, não para além e ao lado de outros, mas apenas no sentido em que usa, com base no seu agir com violência, o poder da violência contra a imponência, isto é, o vigorar o Ser. Destarte, "pelo fato de num sentido originariamente uno ser duplamente deinón, o homem é tò deinótaton, o

\footnotetext{
${ }^{13}$ Idem, ibidem, p. 166.
} 
mais violento: agindo com violência no meio da imponência"14. Heidegger, contudo, chama a atenção para o fato de que

Atribuímos aqui à palavra 'violento' um sentido essencial que extravasa de modo fundamental o significado habitual da palavra, segundo o qual quase sempre se quer dizer brutalidade (Rohheit) e arbitrariedade (Willkür). Neste caso, a violência é vista a partir do contexto em que o critério da existência é constituído com base no acordo do compromisso e da mútua assistência e em que, por conseguinte, qualquer forma de violência é necessariamente avaliada, de modo depreciativo, como interferência perturbadora e infractora ${ }^{15}$.

No fundo, o que Heidegger quer dizer é que essa violência, esse agir violentamente e esse vigor imponente devem ser entendidos ontológicamente, e não ônticamente. A violência ôntica, que é o sentido habitual do termo, dá-se justamente quando ocorre a hýbris do homem proclamar-se "senhor da Terra", compreendendo-se como sujeito agente cuja vontade própria é a causa da sua ação. Para Heidegger, o último estágio da metafísica ocidental, a era da técnica moderna, nada mais é do que a expressão máxima desse desequilíbrio. A interpretação do homem como animal racional, onde o que importa é apenas elevar essa racionalidade, fez com que a vontade do homem se tornasse uma vontade de assenhorar-se do Ser. A vontade de poder nietzcheana, nesse sentido, vira uma vontade de vontade, isto é, querer o querer. É esse homem do humanismo, é dizer, o homem entendido como animal racional, que Nietzsche diz que deve ser superado. Tal homem é designado por Zaratustra como o último homem (der 
letzte Mensch), o mais desprezível dos homens. Ele deve ser superado para a vinda do super-homen (Übermensch).

\begin{abstract}
Mas de onde vem o clamor pela necessidade do super-homem? Por que o homem não é mais suficiente? Porque Nietzsche reconhece o instante histórico em que o homem se prepara para entrar na total dominação da Terra. Nietzsche é o primeiro pensador que, considerando a história do mundo tal como esta pela primeira vez nos chega, coloca a pergunta decisiva e a pensa através de toda sua amplitude metafísica. A pergunta é: o homem enquanto homem, em sua constituição de essência até hoje vigente, está preparado para assumir a dominação da Terra? Se não, o que então precisa acontecer com o homem atual, de modo que ele se "submeta" à Terra e assim cumpra a palavra de um velho testamento? Não será preciso conduzir o homem atual para além de si mesmo, para poder corresponder a esta missão?16
\end{abstract}

A missão, o destino do homem atual, do homem da técnica, é "submeter-se à Terra" ao invés de querer operar o contrário, ou seja, submeter a Terra à sua vontade, ao seu querer. Submeter-se aqui significa: obedecer, saber ouvir. Só quando o homem encontra-se no vigor imponente, violento do Ser, é que ele encontra-se a si próprio. Heidegger assevera que

A enorme distância em que o homem se encontra deslocado da sua própria essência é-nos denunciada pela opinião que ele nutre de si mesmo como aquele que inventou e pôde inventar a linguagem e a compreensão, a edificação e a poesia. Como é que o homem poderia sequer ter inventado o que vigorando o impregna, o envolve, tratando-se afinal aquilo pelo qual ele próprio apenas pode ser homem? (...) Antes, pelo contrário, a linguagem, a compreensão, a disposição, a paixão e a

\footnotetext{
${ }^{16}$ HEIDEGGER, M. Quem é o Zaratustra de Nietzsche? In:
} . Ensaios e conferências, p. 91. 
ANALÓGOS, Rio de Janeiro, Edição Especial, 2017

edificação não pertencem em menor grau ao vigor imponente do que o mar, a terra e o animal. A diferença consiste unicamente no fato de este vigorar imponentemente em torno (umwalten) do homem, suportando-o, impelindo-o e compelindo-o, enquanto que aquele vigora através dele (durchwalten), impregnando-o como aquilo que o homem, como o ente que é, tem de assumir por conta própria17.

Este encontrar-se a si próprio, assumir o seu próprio ser, nada mais é do que assumir aquela violência do que age violenta e imponentemente. A vida deve vigorar não só ao derredor, como também através do homem. $\mathrm{O}$ homem deve ser o pastor e o porta-voz do Ser, o arauto da vida. Quando o homem age violentamente nesse sentido, ele não exerce nenhuma brutalidade nem arbitrariedade de sua vontade, mas ele subjuga, explora, domina e captura em si mesmo a abertura do ente enquanto tal ou qual coisa. Ele abre-se ao Ser enquanto desvelamento sendo forte, e por isso o verdadeiro só se dá para os fortes.

Só quando tivermos entendido que o uso da violência na linguagem, na compreensão, na formação, cria também (mitschaffen) - que significa sempre pro-duz (her-vor-bringen) - o ato violento de abrir caminhos para o ente circunstante, só então compreenderemos a estranheza de tudo aquilo que age com violência 18 .

É pelo fato de o homem estar e agir no lógos, na reunião, é que ele pode ser aquele que reune o vigor imperante da phýsis. Ele assim assume e

\footnotetext{
${ }^{17}$ HEIDEGGER, M. Introdução à Metafísica, pp. 172-173.

${ }^{18}$ Idem, ibidem, p. 174.
} 
ANALÓGOS, Rio de Janeiro, Edição Especial, 2017

exerce a gerência desse vigor imponente. É a partir desse ímpeto do vigor imponente que a palavra, o nomear "repõe o ente que se abre no seu Ser e mantém-no nessa abertura, delimitação e consistência"19. Também a linguagem, enquanto lógos, é co-originariamente violenta. É a essa linguagem que o homem deve apurar os ouvidos, para, ouvindo, obedecer. Esse é o sentido da terra.

Desse modo, quando Zaratustra questiona: "A hora chega - a hora em que sinto frio e estremeço, que pergunta, pergunta e pergunta: 'Quem tem coração bastante para isso? - quem deverá ser o senhor da terra? Quem dirá: assim deveis correr, grandes e pequenos rios!?"'20, sempre haverão duas respostas possíveis. O homem moderno responderá: "Eu!". Mas a real resposta de Zaratrusta, o porta-voz da vida, é: "Senhor da Terra há de ser aquele que obedece ao sentido da Terra".

\section{Referências bibliográficas}

HEIDEGGER, M. Ensaios e conferências. Trad. Emmanuel Carneiro Leão, Gilvan Fogel e Marcia Sá Cavalcante Schuback. Petrópolis: Vozes, 2001. Introdução à Metafísica. Trad. Mário Matos e Bernhard Sylla. Lisboa: Instituto Piaget, 1997.

\footnotetext{
${ }^{19}$ Idem, ibidem, p. 189.

${ }^{20}$ NIETZSCHE, F. Assim falou Zaratustra, p. 304.
} 
Esboço de uma fenomenologia da violência segundo Heidegger Felipe Ramos Gall ANALÓGOS, Rio de Janeiro, Edição Especial, 2017 --_-_-. Ser e Tempo. Trad. Márcia Sá Cavalcante Schuback. Petrópolis: Vozes, 2006.

NIETZSCHE, F. Assim falou Zaratustra. Trad. Paulo César de Souza. São Paulo: Companhia das Letras, 2011. 